\title{
Aplikasi Sistem Informasi Geografis Pemetaan Kawasan Pertambangan Timah Berbasis Web Studi Kasus Di Dinas Pertambangan Dan Energi Kabupaten Bangka Tengah
}

\author{
Heriadi \\ Progam Studi Teknik Informatika \\ STMIK Atma Luhur \\ J1. Jend. Sudirman Pangkalpinang \\ heriadi909@yahoo.com
}

\author{
Delpiah Wahyuningsih \\ Program Studi Teknik Informatika \\ STMIK Atma Luhur \\ Jl. Jend. Sudirman Pangkalpinang \\ delphibabel@atmaluhur.ac.id
}

\begin{abstract}
Abstrak - Kabupaten Bangka Tengah merupakan salah satu kabupaten di Provinsi Kepulauan Bangka Belitung yang memiliki daerah yang cukup luas. Dengan perkembangan teknologi saat ini, untuk mengetahui suatu lokasi kesehatan, pendidikan dan pariwisata cukup mudah dengan bantuan media website, namun untuk lokasi pertambangan belum tersedia, sehingga pemerintah maupun Masyarakat sulit mengetahui lokasi kawasan pertambangan di kawasan Kabupaten Bangka Tengah yang memiliki izin resmi. Oleh karena itu, salah satu cara untuk membantu masyarakat dalam mencari informasi adalah dengan membuat aplikasi sistem informasi geografis yang dapat memberikan informasi lokasi kawasan pertambangan dengan menggunakan media website. Dengan memanfaatkan WebGIS ini, titik lokasi kawasan pertambangan akan ditampilkan sedetail mungkin dalam tampilan web yang sederhana sehingga mudah digunakan pemerintah maupun masyarakat. Aplikasi ini akan memberikan kemudahan dalam mengakses informasi dengan cepat dan akurat untuk menghemat biaya dan waktu. Penerapan aplikasi ini akan berdampak positif bagi masyarakat dan pemerintah Bangka Tengah
\end{abstract}

Kata Kunci- Webgis, Sistem Informasi Geografis, kawasan pertambangan

\section{Pendahuluan}

Kabupaten Bangka Tengah dibentuk pada tanggal 25 Februari 2003 berdasarkan Undang-undang Nomor 5 Tahun 2003. Bersama-sama dengan pembentukan Kabupaten Bangka Tengah, dibentuk pula Kabupaten Bangka Selatan, Bangka Barat dan Belitung Timur. Wilayah Kabupaten Bangka Tengah Tengah terletak di Pulau Bangka. Secara administratif wilayah Kabupaten Bangka Tengah berbatasan langsung dengan daratan wilayah kabupaten / kota lainnya di Provinsi Kepulauan Bangka Belitung, yaitu dengan wilayah Kota Pangkalpinang, Kabupaten Bangka, dan Bangka Selatan. Pembentukan Kabupaten Bangka Tengah tidak semata-mata karena kebutuhan pengembangan wilayah provinsi, tetapi juga karena keinginan masyarakat di dalamnya, serta upaya untuk mempercepat pembangunan daerah dan terciptanya pelayanan publik yang lebih efektif dan efisien.

Kota Koba merupakan daerah yang strategis ditinjau dari segi geografisnya, terutama dalam kaitannya dengan pertambangan dan pembangunan Provinsi Kepulauan Bangka Belitung. Kota Koba juga sebagai pusat pengembangan pembangunan perdagangan, pendidikan, dan tidak lepas dari pertambangan. Sistem Informasi Geografis ini diharapkan dapat membantu Pemerintah dalam mengakses kawasan pertambangan yang dilakukan oleh perusahaan pertambangan maupun masyarakat sehingga dapat dipantau letak kawasan pertambangan yang ada Kabupaten Bangka Tengah khususnya di Koba.

Seiring dengan perkembangan komputer, perkembangan SIG juga mengalami peningkatan yang sangat pesat. Peningkatan itu terutama terdorong oleh perkembangan pengindraan jauh, komputer, dan global positioning system (GPS). Perkembangan SIG sangat menarik bagi berbagai pihak untuk keperluan yang sangat beragam. Oleh karena itu, penggunaan SIG mengalami peningkatan yang sangat pesat sejak 1980-an. Peningkatan penggunaan SIG terjadi terutama di negara-negara maju, baik di kalangan militer, pemerintahan, akademis, maupun untuk kepentingan bisnis. Kita ketahui bahwa salah satu fungsi peta adalah untuk menyimpan data geografis. Pada mulanya data-data geografis tersebut disajikan dengan menggunakan simbol-simbol tertentu. Oleh karena itu, peta dapat dianggap sebagai media yang efektif untuk menyimpan dan menginformasikan data geografis. Namun, seiring dengan kemajuan ilmu dan teknologi, data-data informasi geografis dapat disampaikan dengan menggunakan perangkat komputer. Data-data dalam komputer itu dikenal dengan istilah data digital.

Keterbatasan informasi mengenai kawasan pertambangan tersebut dapat menghambat pemerintah maupun masyarakat untuk mengetahui letak dan batasan kawasan pertambangan terutama Dinas Pertambangan dan Energi dalam mendapatkan informasi yang diperlukan dengan cepat. 


\section{Metode Penelitian}

Metodelogi penelitian yang dilakukan dalam penulisan ini adalah sebagai berikut:

\section{A. Pengumpulan Data}

1) Obeservasi

Adalah kegiatan yang dilakukan sebelum pelaksanaan kegiatan pengumpulan data dengan melakukan pengenalan terhadap objek penelitian yang meliputi lingkungan kerja, aktifitas bekerja dan bahan kajian.

\section{2) Wawancara}

Dilakukan dengan orang yang memiliki wewenang dan tanggung jawab yang diperlukan, dalam kasus ini adalah Sekretaris Dinas Pertambangan dan Energi Kabupaten Bangka Tengah sehingga informasi dan data yang diterima di dapatkan secara tepat dan akurat.

\section{3) Studi Literatur}

Pada metode ini, penulis membaca dan menelaah berbagai data dari buku atau literatur yang ada diinternet yang berhubungan dengan GPS (Global Positioning System) dan masalah yang akan dibahas.

\section{B. Analisis dan Rancangan}

Dalam merancang aplikasi ini tentunya memerlukan analisis yang akan membantu dalam menganalisa apa saja yang akan digunakan dalam pembuatan aplikasi nantinya. Perancangan sebuah aplikasi yang akan di lakukan pada laporan skripsi ini merupakan suatu rancangan aplikasi Quantum GIS dimana yang nantinya akan digunakan untuk melengkapi aplikasi yang di rancang, Perangkat lunak yang di gunakan adalah Quantum GIS.

\section{Pengembangan Perangkat Lunak}

Dalam metode pegembangan perangkat lunak penulis menggunakan metode Oose ( Object Oriented Software Enginering), pada rancangan dan mekanisme aplikasi sistem informasi Geografis pemetaan kawasan pertambangan timah berbasis web ini di bangun menggunakan UML ( Unified Modeling Languange) diantaranya adalah Use Case Diagram dan Activity diagram. Rancangan dan mekanisme yang dibuat terbagi dalam beberapa tahapan yaitu sebagai berikut :

1) Tahap Analisa Sistem

Pada tahap analisa sistem penulis melakukan analisa kebutuhan sistem untuk mengidentifikasi terhadap kebutuhan sistem baru. Adapun kebutuhan sistemnya adalah analisis kebutuhan data, analisis proses, kebutuhan User dan Admin serta analisis kebutuhan SIG (Sistem Informasi Geografis) pemetaan kawasan pertambangan timah di Bangka Tengah. Sistem akan memproses data dan menampilkan kepada admin yang tersimpan dalam database. Fungsi dari analisis sistem adalah untuk memberikan gambaran perancangan sistem serta memahami proses informasi dalam sistem. Adapun tool yang digunakan adalah :

\section{a) Activity Diagram}

Dalam tahap awal ini, Activity Diagram akan menggambarkan proses bisnis dan urutan aktifitas didalam suatu proses.

\section{b) Analisa Masukan}

Dalam tahap ini, analisa masukan bertujuan untuk melihat proses pada pengumpulan data untuk mendapatkan data-data informasi

\section{c) Analisa Keluaran}

Analisa keluaran bertujuan untuk melihat hasil keluaran dalam proses pada sistem yang berjalan.

\section{d) Use Case Diagram}

Pada tahap ini, Use case Diagram bertujuan untuk menjelaskan manfaat sistem yang berjalan di dalam sebuah sistem dan siapa saja yang mempunyai hak untuk menggunakan fungsi tersebut yang berada di luar sistem atau actor.

\section{e) Deskripsi Use Case}

Pada tahap ini berfungsi untuk mendeskripsikan secara rinci mengenai Use Case Diagram.

\section{2) Tahap Perancangan Sistem}

Dalam tahap ini melakukan proses perancangan antarmuka dan perancangan database. Adpun tool yang digunakan penulis adalah :

\section{a) Rancangan Proses}

Dalam tahap akan membahas bagaimana proses dalam pembuatan aplikasi yang digambarkan dengan menggunakan flowchart.

\section{b) Rancangan masukan}

Dalam tahap rancangan masukan bertujuan untuk memasukan data yang berjalan.

\section{c) Rancangan keluaran}

Dalam tahap rancangan keluaran bertujuan untuk merancang suatu Proses pembuatan sistem yang telah di buat.

d) Rancangan layar

Pada tahap ini rancangan layar bertujuan untuk merancang website yang telah dibuat berdasarkan kebutuhan sistem informasi geografis berbasis web.

e) Rancangan basis data

Dalam tahap ini, bertujuan untuk menjelaskan tentang Entity Diagram Relationship (ERD), Transformasi ERD ke LRS, Logical Record Structure (LRS), Tabel dan Spesifikasi Basis Data. 


\section{f) Rancangan Peta}

Pada tahap ini bertujuan untuk proses awal atau rancangan dalam pembuatan peta yang menggunakan Software Quantum GIS 1.8.0-Lisboa.

\section{g) Rancangan Website}

Pada tahap ini bertujuan sebagai menyampaikan bentuk informasi kepada Admin dan User.

\section{3) Tahap Implementasi}

Tujuan dari tahap ini adalah untuk menterjemahkan perancangan berdasarkan anaisis dalam bahasa yang mudah dimengerti oleh mesin dan penerapan perangkat lunak yang sebenarnya.

\section{4) Pembahasan}

Dalam tahap ini bertujuan untuk menjelaskan sistem informasi geografis yang akan dibangun mengenai tahapan perancangan antar muka. Adpaun pembahasannya adalah sebagai berikut :

a) Hasil Tampilan Peta Pada Pmapper

Pada tahap ini bertujuan untuk menghasilkan tampilan peta pada Pmapper yang sesuai dengan gambaran lokasi yang ada di Bangka Tengah.

\section{b) Pengujian Peta Pada Pmapper}

Pada tahap ini bertujuan untuk memberikan pengujian hasil proses peta yang akan dibahas pada letak lokasi pemetaan kawasan pertambangan yang ada di Kabupaten Bangka Tengah.

\section{c) Pengujian Webgis}

Pada tahap ini penulis akan melakukan pengujian terlebih dahulu untuk melihat fungsi dari seluruh menu pada aplikasi Webgis ini apakah berjalan dengan baik atau sebaliknya.

\section{HASIL DAN PEMBAHASAN}

\section{A. Proses Digitasi Peta}

Dalam tahap proses membuat peta akan menggunakan Sofware Quantum GIS 1.8.0- Lisboa. hasil digitasi dari plugins Quantum GIS 1.8.0-Lisboa adalah Peta Polygon dan Line yang dibuat berupa Google Street Layer, sedangkan untuk titik koordinatnya yang merupakan pembuatan peta Point untuk Tambang diambil dari lokasi pertambangan yang di ambil oleh tim survei dari Dinas Pertambangan dengan menggunakan GPS (Global Positioning System).

\section{1) Proses Pembuatan Peta}

Pada proses awal pembuatan peta merupakan hasil digitasi dari plugins Quantum GIS 1.8.0-Lisboa yang merupakan dari Google Street Layer. a) Digitasi peta kepulauan Bangka Belitung

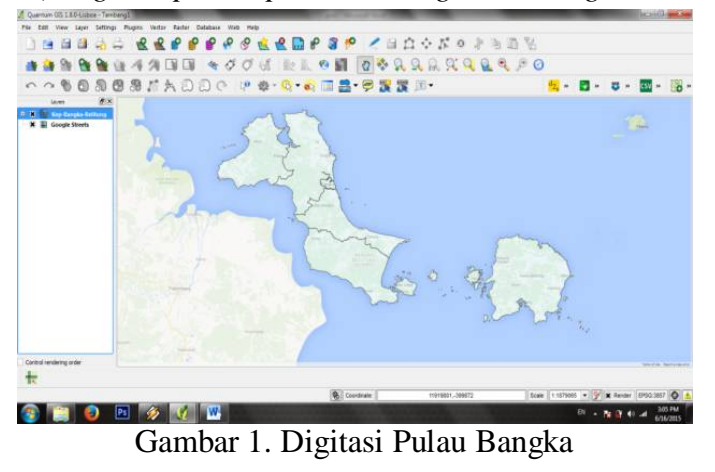

\section{b) Hasil Digitasi Pulau Bangka}

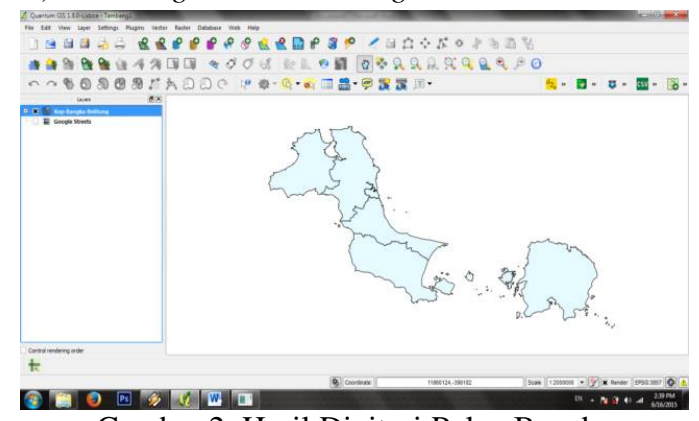

Gambar 2. Hasil Digitasi Pulau Bangka

c) Digitasi Peta Kecamatan Sungai Selan

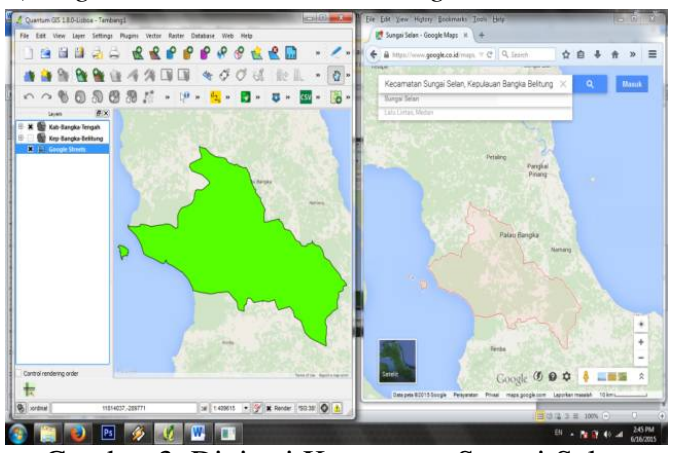

Gambar 3. Digitasi Kecamatan Sungai Selan

d) Hasil Digitasi Peta kabupaten Bangka Tengah

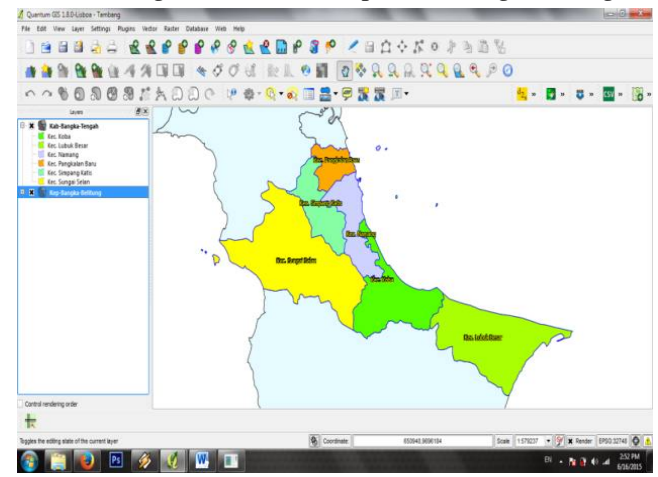

Gambar 4. Hasil Digitasi Peta Kabupaten Bangka Tengah 
e) Hasil Digitasi jalan kabupaten Bangka Tengah

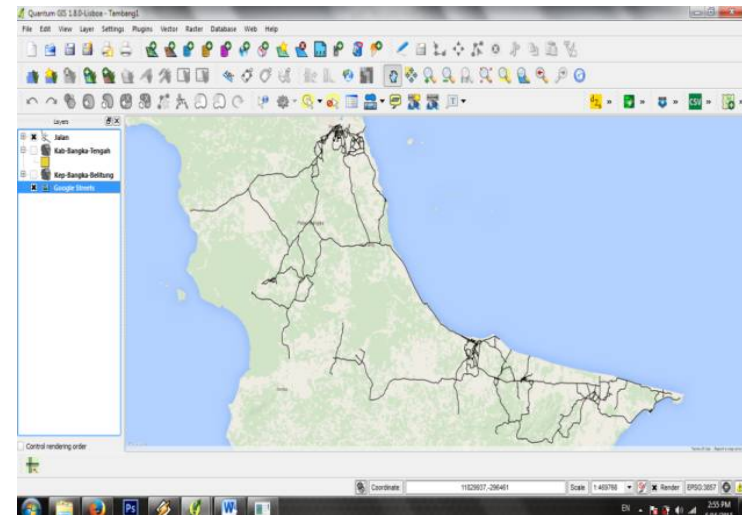

Gambar 5. Hasil Digitasi Jalan Kabupaten Bangka Tengah

\section{f) Menginput Titik Koordinat Wilayah Pertambangan}

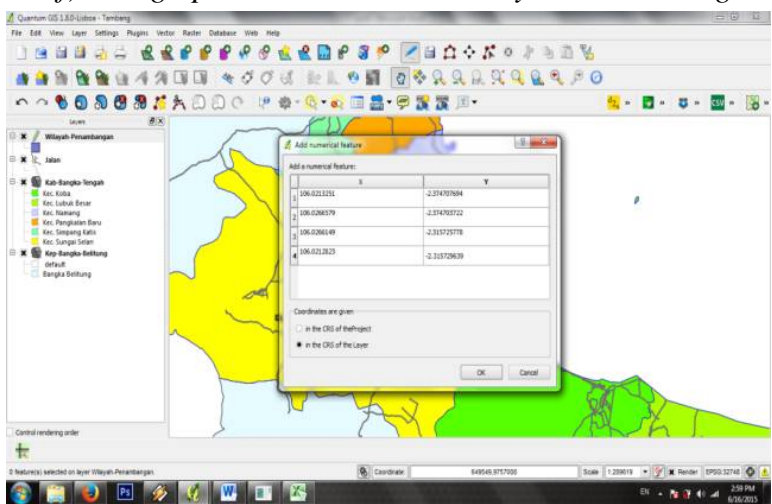

Gambar 6. Menginput Titik Koordinat Wilayah Pertambangan

g) Hasil Penginputan Titik Koordinat Wilayah Pertambangan

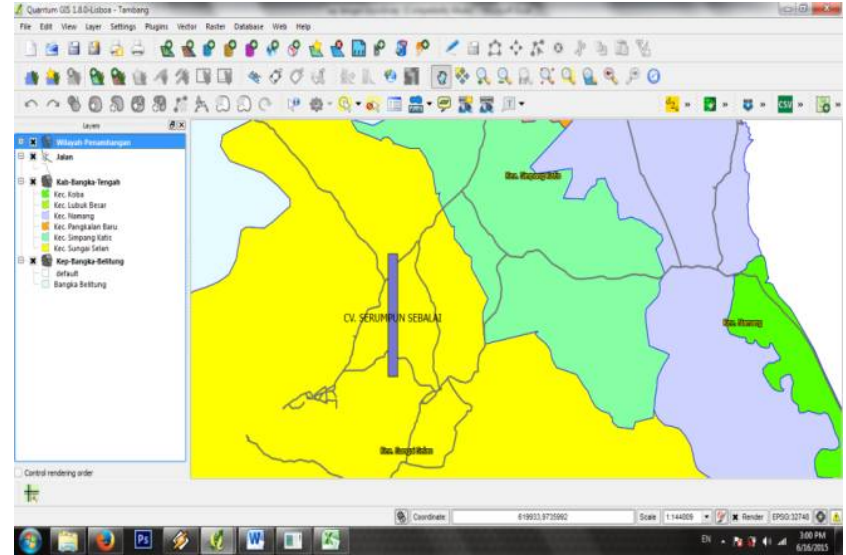

Gambar 7. Hasil Penginputan

h) Hasil Penginputan Seluruh Titik Koordinat Wilayah Pertambangan

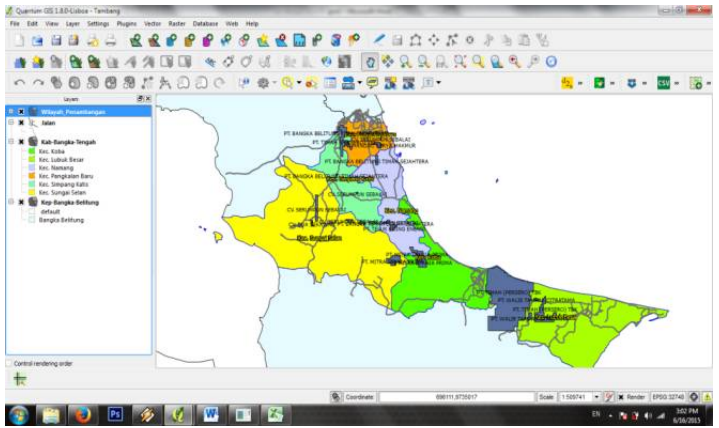

Gambar 8. Hasil Seluruh Penginputan TItik Koordinat

i) Hasil Jadi Pemetaan Wilayah Pertambangan di Kabupaten Bangka Tengah

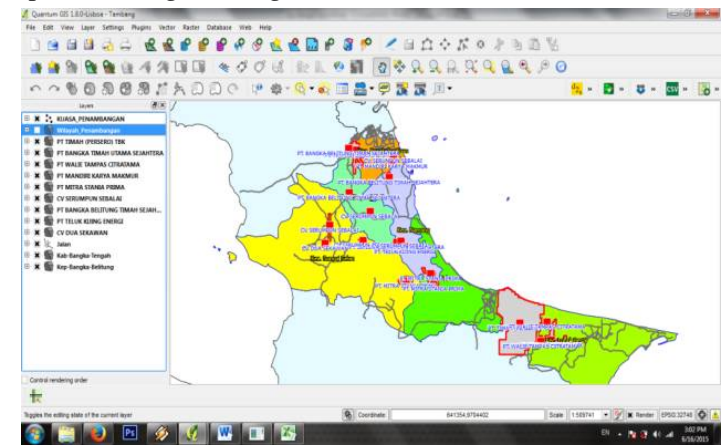

Gambar 9. Hasil Jadi Pemetaan Wilayah Pertambangan

\section{2) Rancangan Basis Data}

Rancangan basis data merupakan proses untuk menciptakan rancangan basis data yang akan mendukung operasi dan tujuan suatu rangkaian sistem yang ada. Rancangan basis data terdiri dari :

a) Entity Relatioship Diagram

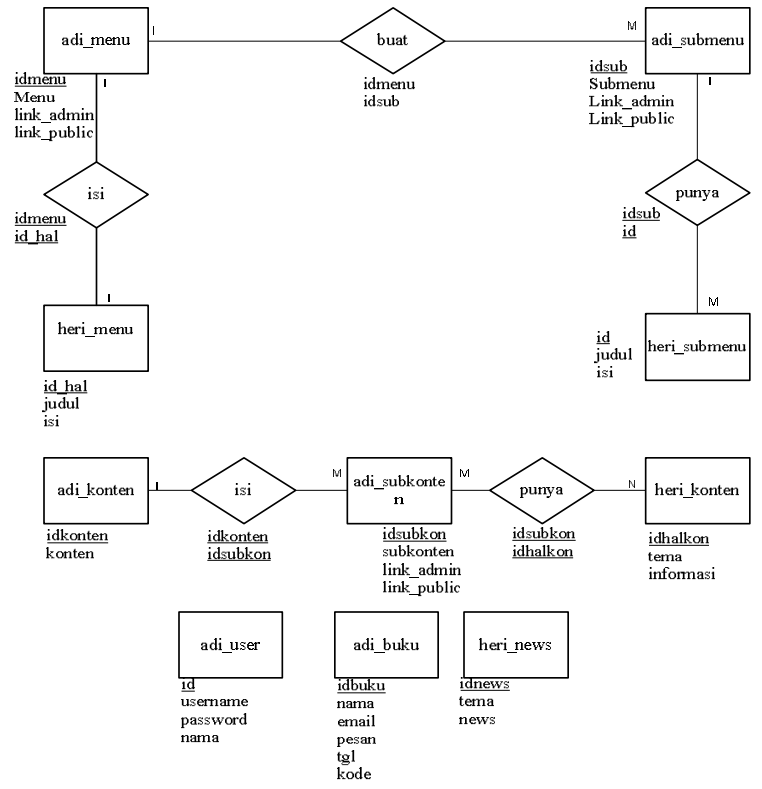

Gambar 10. Entity Relationship Diagram 
b) Transformasi ERD ke LRS
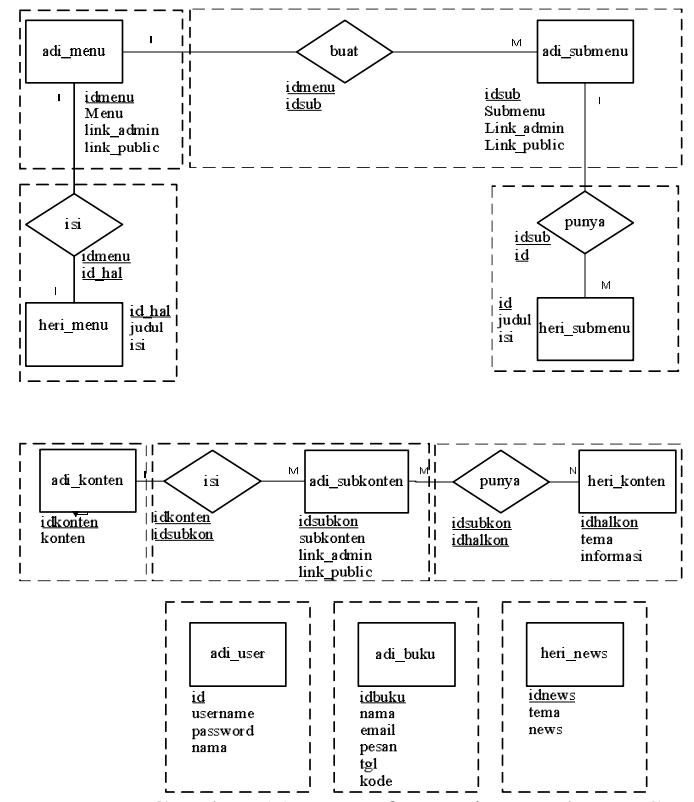

Gambar 11. Transformasi ERD ke LRS

\section{c) Logical Record Structure}
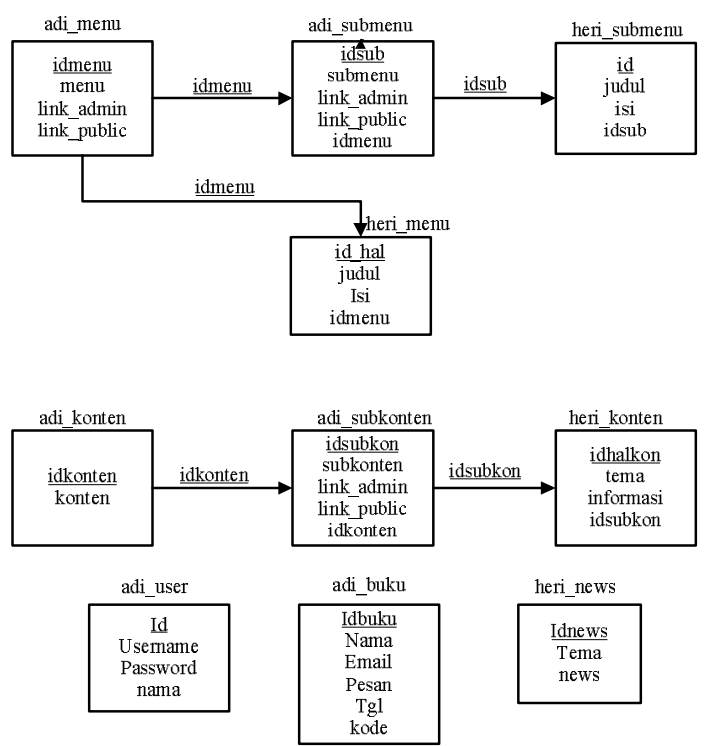

Gambar 12. Logical Record Structure

\section{3) Rancangan Website}

Dalam tampilan website memiliki peranan penting karena sebagai bentuk penyampaian informasi kepada pengguna agar lebih menarik untuk di lihat oleh user maupun pengunjung website tersebut, Pada aplikasi website ini di rancang lebih sederhana. Pada tahap desain website menggunakan bahasa pemrograman PHP dan CSS. Berikut ini adalah tampilan print screen dari halaman website :

\section{a) Tampilan Home}

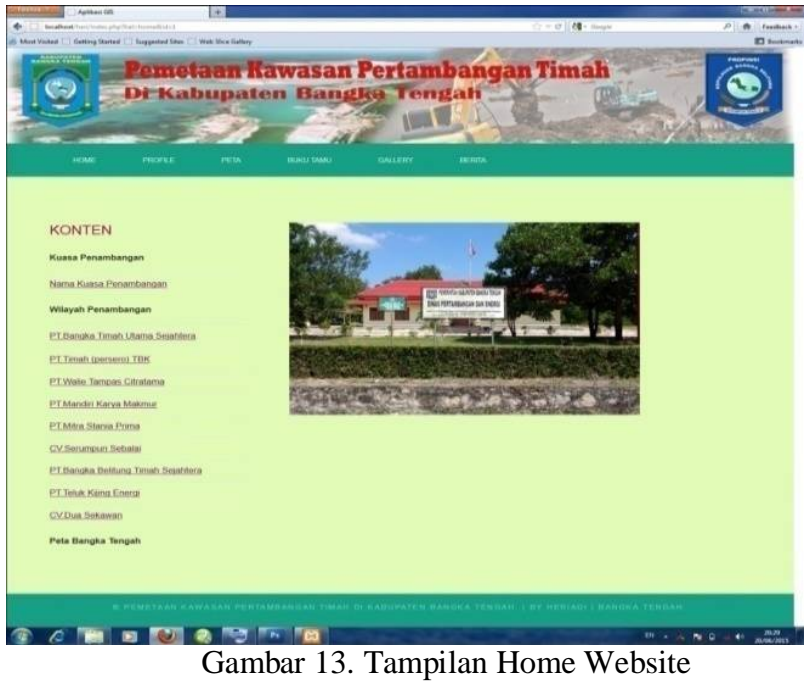

\section{PEMBahasan}

Dalam tahap ini dilakukan untuk mengetahui apakah sistem yang dibangun telah berjalan dengan baik atau sudah memenuhi spesifikasi yang telah ditentukan. Pada bagian ini akan membahas tentang tahapan perancangan antarmuka. Sistem yang dibangun adalah aplikasi yang berbasis web, sehingga antarmuka yang dibangun adalah antarmuka web. Dalam perancangan pembangunannya akan dirancang sesederhana mungkin sehingga user bisa menggunakannya dengan mudah.

\section{A. Hasil Tampilan Peta Pada Pmapper}

Dalam tampilan halaman ini merupakan halaman yang menampilkan visualisasi peta Wilayah Bangka Tengah yang dilengkapi dengan kemampuan navigasi peta seperti show all, zoom in, zoom out, recenter, informasi, reference map, scalebar dan legend dari semua bidang.

\section{1) Gambar Tampilan Titik Lokasi Tambang}

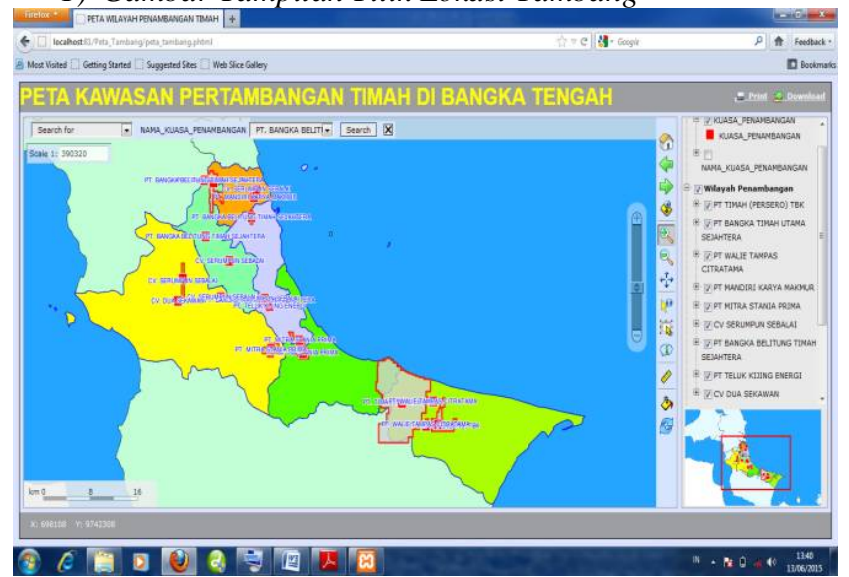

Gambar 14. Tampilan Titik Lokasi Tambang 
2) Gambar Tampilan Peta Dari Semua Legenda Yang Diaktifkan

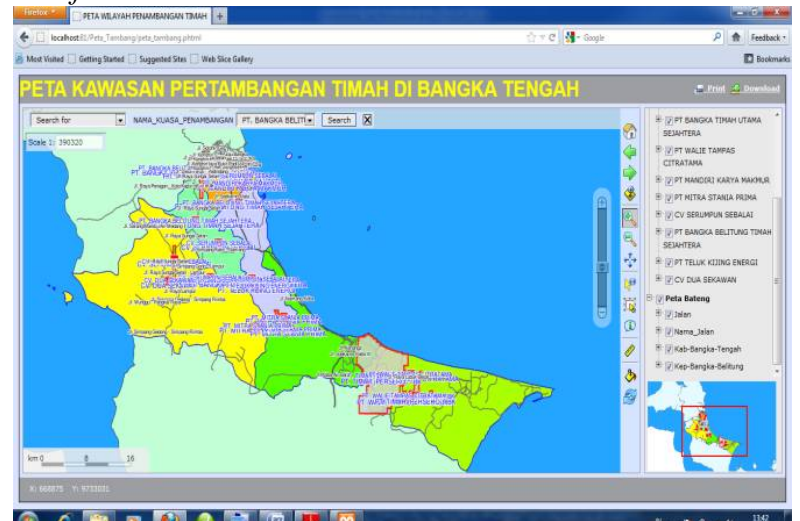

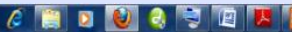

Gambar 15. Tampilan Peta dari Semua Legenda yang Diaktifkan

\section{B. Pengujian Peta Pada Pmapper}

\section{1) Penggunaan Tool Search For}

Tool Search for digunakan untuk mencari lokasi tambang dan wilayah izin pertambangan secara detail berdasarkan nama perusahaan yang ada. Tool ini berfungsi sebagai mempercepat pencarian wilayah izin pertambangan.

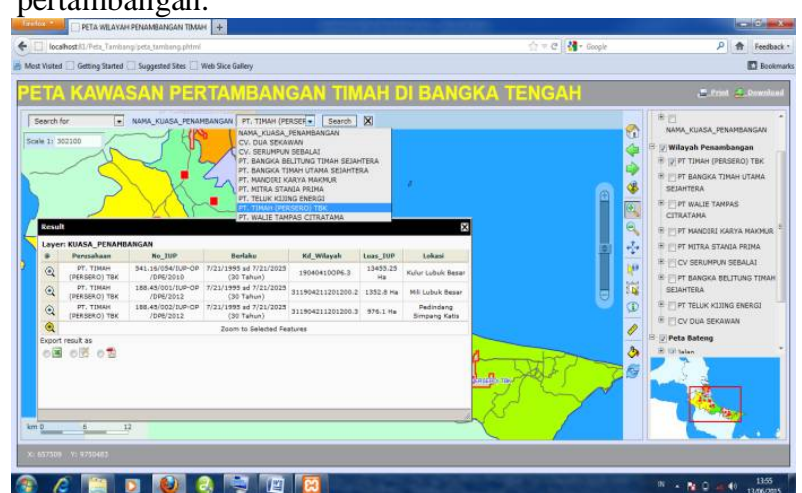

Gambar 16. Penggunaan Tool Search For

\section{2) Penggunaan Tool Select}

Tools Select digunakan untuk mencari informasi dari data pertambangan berdasarkan titik lokasi dan dengan mengklik gambar titik tambang tersebut.

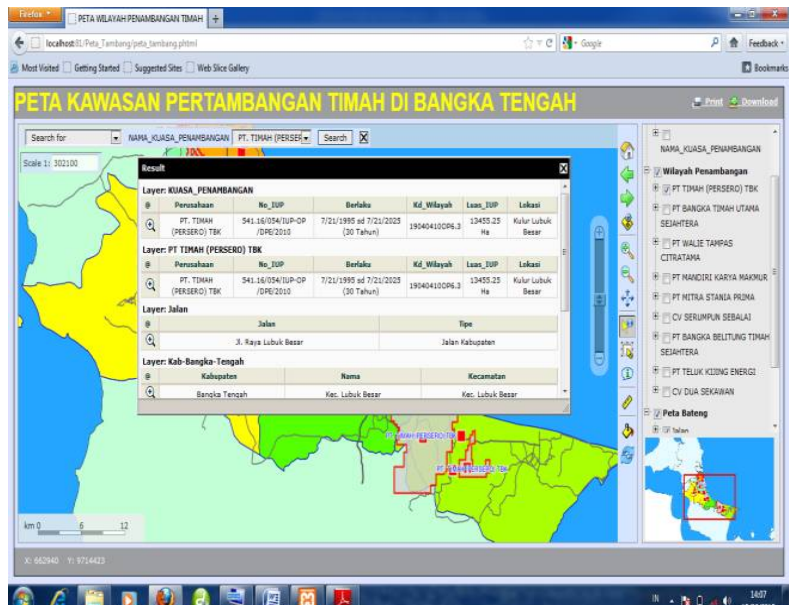

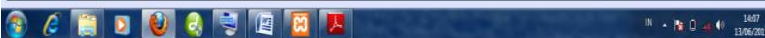

Gambar 17. Penggunaan Tool Select

\section{3) Penggunaan Tool Download}

Tools Download digunakan untuk menyimpan dokumen keluaran peta. Peta dapat di download dengan kualitas yang diinginkan sesuai settingan. kemudian pilih GeoTIFF dan pada form opening mapdownload pilih save file agar dapat di download langsung.

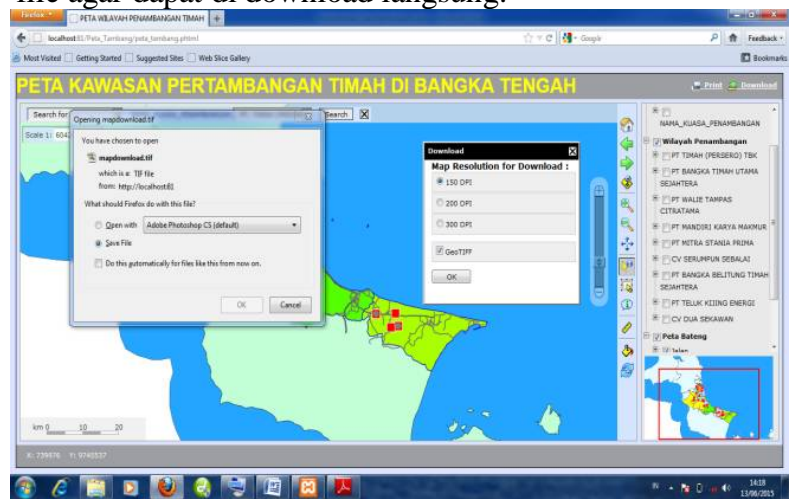

Gambar 18. Penggunaan Tool Download

\section{Penutup}

\section{A. Kesimpulan}

Dalam pembuatan aplikasi Sistem Informasi Geografis pemetaan kawasan pertambangan timah berbasis web yang ada di Bangka Tengah ini dapat disimpulkan sebagai berikut :

- Dengan adanya aplikasi ini pemerintah maupun masyarakat bisa dengan mudah untuk mencari dan mendapatkan informasi tentang letak kawasan pertambangan yang ada di Bangka Tengah.

- Sistem yang dibangun dapat memberikan informasi tentang kawasan pertambangan selama 24 jam melalui WebGis.

- Dibangunnya sistem informasi geografis ini, pemerintah maupun masyarakat dapat mengetahui letak, luas area pertambangan timah dan nama 
perusahaan yang memilki izin resmi yang mengelola pertambangan tersebut di daerah Bangka Tengah.

\section{B. Saran}

Aplikasi Sistem Informasi Geografis ini masih jauh dari sempurna dan masih banyak kekurangannya. Oleh karena itu perlu pengembangan dan penyempurnaan lebih lanjut yang berguna untuk pebaikan dari sistem ini, adapun saran agar aplikasi ini dapat berfungsi lebih optimal adalah :

- Fasilitas pencarian informasi peta yang ditampilkan dapat dikembangkan sesuai kebutuhan dalam pengembangan sistem tersebut.

- Diharapkan informasi yang disajikan dapat ditambah lebih lengkap, tidak hanya data kawasan pertambangan timah di Kabupaten Bangka Tengah saja, tetapi juga di seluruh kawasan Provinsi Bangka Belitung.

- Agar penyampaian informasi peta lebih lengkap, sebaiknya ditambahkan data spasial denah.

\section{DAFTAR PUSTAKA}

[1] Ramadona, Aditya dan Hari Kusnanto. Open Source GIS (Aplikasi Quantum GIS Untuk Sistem Informasi Lingkungan). BPFE. Yogyakarta. 2012.

[2] Komputer, Wahana. 2013. Adobe Dreamweaver CS6. CV Andi Offset. Yogyakarta.

[3] Indarto, Sistem Informasi Geografis, Yogyakarta: Graha Ilmu, 2013.

[4] Taufik, Rahmat, Sistem Informasi Manajemen ( Konsep Dasar, Analisis dan Metode Pengembangan ), Yogyakarta:Graha Ilmu, 2013.

[5] Akmal, Galih Dwi Nisa, Membangun Sistem Informasi Geografis Pemetaan Perguruan Tinggi Di DIY Berbasis Web, Yogyakarta: STMIK AMIKOM, 2011.

[6] Kusrianto, Adi. 2005. Panduan Lengkap Memakai Microsoft Office Project 2003. PT Elex Media Komputindo. Jakarta

[7] Sarwono, Jonathan. 2012. Metode Riset Online: Teori, Praktik, dan Pembuatan Aplikasi (Menggunakan HTML, PHP, dan CSS). PT Elex Media Komputindo. Jakarta.

[8] A. S. , Rosa dan M. Shalahuddin. 2013. Rekayasa Perangkat Lunak Terstruktur dan Berorientasi Objek. Informatika. Bandung.

[9] Faradiansyah, Yoga. 2011. Sistem Informasi Objek Pariwisata Pada Kabupaten Banyumas Berbasis Mobile. STMIK AMIKOM. Yogyakarta.

[10] F.K. Sibero, Alexander. 2012. Kitab Suci Web Programing. Mediakom. Yogyakarta. 